\title{
Modification of jute by use of triethylenetetramine and its adsorption behavior for copper (II)
}

\author{
Y.M. Feng ${ }^{1}$ \& Z.L. DU ${ }^{1} \&$ T. ZHENG $^{1^{*}}$ \& P. WANG ${ }^{1,2}$ \\ ${ }^{1}$ School of Municipal and Environmental Engineering, Harbin Institute of Technology, 150090 \\ Harbin, China; \\ ${ }^{2}$ State Key Laboratory of Urban Water Resource and Environment, 150090 Harbin, China
}

Keywords: modified jute fiber; adsorption; copper ions; amino groups;

\begin{abstract}
An efficient adsorbent for $\mathrm{Cu}$ (II) removal from aqueous solution was synthesized by grafting amino group onto jute fiber. The fiber was chemically modified by two steps, loading of epoxy chloropropane and triethylenetetramine. Properties of the modified jute such as surface chemical structure, tensile strength and adsorption capacity on different environmental conditions were conducted. The results show that the adsorption capacity of the modified jute on $\mathrm{Cu}$ (II) is 120.048mg. $\mathrm{g}^{-1}$ at $30^{\circ} \mathrm{C}$, and the modified jute has strong anti-interference ability.
\end{abstract}

\section{Introduction}

The removal of heavy metal ions in the emergency water treatment can be achieved by several methods. Among these methods, adsorption method is widely used as disposal technology in our country ${ }^{[2]}$. Activated carbon that is available in large quantities, but practical applications required bagging treatment. which can lead to larger fluid resistance, and reduce the adsorption efficiency ${ }^{[12]}$. At present, the cotton fiber, straw fiber, corn stalks, sawdust, bagasse ${ }^{[11 / 7 / 4]}$ and other materials have been used to prepare a chelating fiber, but more material prepared as a powder, it is difficult to adapt to the requirements of emergency water treatment. Jute fiber is inexpensive and available in large quantities, and has good ability to resist shear, facilitate direct delivery and recovery in practice, which can realize low flow resistance, high mass transfer adsorption treatment effect. In this paper, jute fiber was studied to determine its efficiency in removing of copper from simulated contaminated samples. In order to increase the adsorption capacities, jute fiber was modified by two-step reaction. The effects of the polyamine type of heavy metal ions adsorbed material has good performance and has important environmental benefits.

\section{Experimental}

\section{Materials}

Firstly, jute was cleaned to remove surface floating dust, and then boiling for $30 \mathrm{~min}$ to make some organic dissolution, after that jute was drying at $70^{\circ} \mathrm{C}$. Pretreatment was going with a certain concentration of $\mathrm{NaOH}$ solution soaking $30 \mathrm{~min}$ and then washing to neutral using deionized water, after that jute was drying at $70^{\circ} \mathrm{C}$.In the grafting reaction, the experimental conditions were $1 \mathrm{~g}$ jute after pretreatment, taking DMF as solvent, under the condition of $90^{\circ} \mathrm{C}$ water bath conditions. The epoxy chloropropane was joint to the solvent as first step reaction; at second step, adding triethylenetetramine. After grafting, jute was filtrated several times and then dried at $70^{\circ} \mathrm{C}$.

\section{Adsorption tests}

The effect of experimental parameters such as temperature, $\mathrm{pH}$, coexisting ions, adsorption isotherms and thermodynamics of $\mathrm{Cu}$ (II) were investigated. The impact of temperature and $\mathrm{pH}$ were studied via adding suitable amount of jute before and after modification at different temperature and $\mathrm{pH}$ respectively. After $3 \mathrm{~h}$ adsorption reaction, $\mathrm{Cu}$ (II) concentration of the solution was measured. We chosen $\mathrm{K}^{+}, \mathrm{Na}^{+}, \mathrm{Ca}^{2+}, \mathrm{Mg}^{2+}$ as coexisting ions containing different concentrations respectively, the initial concentration of $\mathrm{Cu}$ (II) was $300 \mathrm{mg} . \mathrm{L}^{-1}$, at the same time, adding suitable amount of modified jute, the adsorption results were measured for $3 \mathrm{~h}$ at room 
temperature.

\section{Analytical methods}

The infrared spectra of the jute before and after modification were analyzed by the PerkinElmer Spectrum One B Fourier Transform Infrared (FT-IR) spectrometer. Surface morphology analysis (SEM) was analyzed by field emission environmental scanning electron microscope magnified 5000 times after spraying gold. And mechanical strength test was analyzed by using electronic universal material testing machine. When the adsorption behavior reached equilibrium, biscy clohexanone oxaldihydrazone spectrophotometer ${ }^{[12]}$ was used to determine the concentration of $\mathrm{Cu}\left(\mathrm{R}^{2}=0.9996\right)$. Jute for $\mathrm{Cu}(\mathrm{II})$ adsorption capacity is calculated as follows:

$$
q_{e}=\frac{\left(C_{0}-C_{e}\right) V}{m}
$$

Where $\mathrm{q}_{\mathrm{e}}$ is the equilibrium adsorption capacity/mg.g-1; $\mathrm{C}_{0} 、 \mathrm{C}_{\mathrm{e}}$ is initial solution and adsorption equilibrium $\mathrm{Cu}$ (II) concentration $/ \mathrm{mg}^{-\mathrm{L}^{-1}} ; \mathrm{V}$ is the volume of solution/L; $\mathrm{m}$ is the adsorbent dosing quantity/g.

\section{Results and discussion}

\section{Preparation of modified Jute}

The preparation routes of the modified jute are shown in the following. According to the synthetic route, we designed the $\mathrm{L}_{9}\left(3^{4}\right)$ level of form factors by modified jute for $\mathrm{Cu}$ (II) adsorption. Each set of experiment was performed twice, and the results were compared using analysis of variance.

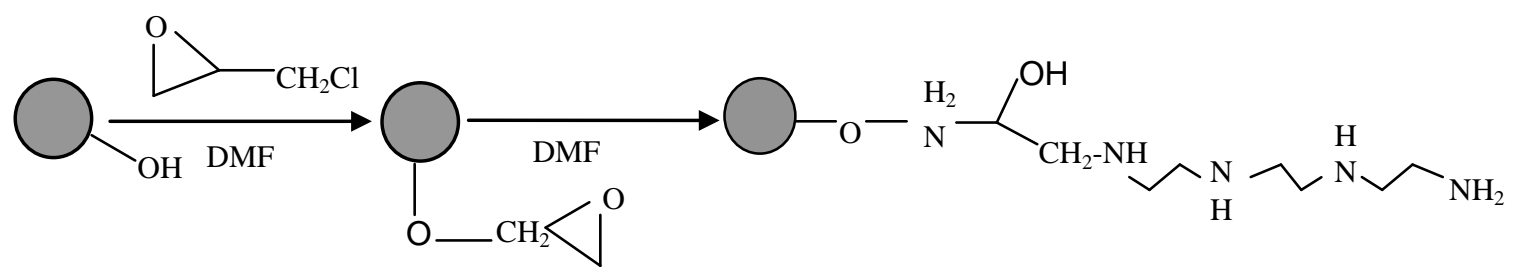

Table 1 Factors and levels table of orthogonal experiment

\begin{tabular}{rcccc} 
A temperature & $\begin{array}{c}\text { B } \\
/^{\circ} \mathrm{C}\end{array}$ & $\begin{array}{c}\text { Epoxy chloropropane: } \\
\text { triethylenetetramine } / \mathrm{mL}\end{array}$ & $\begin{array}{c}\text { C Etherification } \\
\text { time/h }\end{array}$ & $\begin{array}{c}\mathrm{D} \\
\text { Amination } \\
\text { time/h }\end{array}$ \\
\hline 1 & 90 & $10: 5$ & 0.5 & 0.5 \\
3 & 70 & $5: 5$ & 3 & 1 \\
\hline
\end{tabular}

When we analysed the influence of different elements in the grafting reaction, we used the saturated adsorption capacity of $\mathrm{Cu}$ (II) to describe the property of modified jute. And the results were shown in Table 2. As shown in Table 2, the effect of the four factors was significant, indicating a successful graft. And at the same time, by comparison kij values, we chosen A1B1C2D3 as the optimal combination. In order to describe the results significantly, we used variance analysis to analysis the experimental data, and the results were shown in Table 3.

Table 2 Intiutive analysis method

\begin{tabular}{ccccccc}
\hline $\begin{array}{c}\text { experimental } \\
\text { group }\end{array}$ & A & B & C & D & $\begin{array}{c}\text { Qe / } \\
\text { mg.g }^{-1}\end{array}$ & $\begin{array}{c}\text { Qe/ } \\
\text { mg.g }\end{array}$ \\
\hline 1 & 90 & $10: 5$ & 0.5 & 0.5 & 70.713 & 72.791 \\
2 & 90 & $5: 5$ & 1 & 1 & 72.045 & 79.951 \\
3 & 90 & $5: 10$ & 3 & 3 & 82.586 & 86.272 \\
4 & 70 & $10: 5$ & 1 & 3 & 57.290 & 52.289 \\
5 & 70 & $5: 5$ & 3 & 0.5 & 20.356 & 24.983 \\
6 & 70 & $5: 10$ & 0.5 & 1 & 21.561 & 19.133 \\
7 & 50 & $10: 5$ & 3 & 1 & 29.345 & 22.071
\end{tabular}




\begin{tabular}{|c|c|c|c|c|c|c|}
\hline 8 & 50 & 5:5 & 0.5 & 3 & 13.640 & 14.806 \\
\hline 9 & 50 & $5: 10$ & 1 & 0.5 & 10.018 & 16.968 \\
\hline $\mathrm{k}_{1 \mathrm{j}}$ & 77.393 & 50.750 & 35.441 & 35.972 & & \\
\hline $\mathrm{k}_{2 \mathrm{j}}$ & 32.602 & 37.630 & 48.093 & 40.684 & & \\
\hline $\mathrm{k}_{3 \mathrm{j}}$ & 17.808 & 39.428 & 44.269 & 51.147 & & \\
\hline range & 59.585 & 13.120 & 12.652 & 15.175 & & \\
\hline $\begin{array}{l}\text { Factor main- } \\
>\text { minor }\end{array}$ & \multicolumn{4}{|c|}{$\mathrm{A}>\mathrm{D}>\mathrm{B}>\mathrm{C}$} & & \\
\hline & & ble 3 An & sof variance & & & \\
\hline $\begin{array}{l}\text { Sources of } \\
\text { variance }\end{array}$ & Sum of squares & $\begin{array}{l}\text { Freedom } \\
\text { of motion }\end{array}$ & $\begin{array}{c}\text { Mean } \\
\text { square }\end{array}$ & F value & $F_{0.05}$ & ${ }_{\mathrm{t}}$ Significan \\
\hline A & 2887.734 & 2 & 1443.867 & 110.451 & \multirow{4}{*}{4.26} & $* * *$ \\
\hline B & 152.416 & 2 & 76.208 & 5.830 & & $*$ \\
\hline $\mathrm{C}$ & 126.315 & 2 & 63.157 & 4.831 & & * \\
\hline D & 180.979 & 2 & 90.489 & 6.922 & & $*$ \\
\hline Error & 117.653 & 9 & 13.073 & & & \\
\hline$S S_{T}$ & 3465.097 & 17 & & & & \\
\hline
\end{tabular}

F test showed that: the impact of temperature on the grafting reaction is extremely significant, the amination time and reagent ratio on jute modification effect significantly. In summary, after the reaction jute fiber has been connected to the corresponding groups, and optimal reaction conditions are $A_{1}$ (grafting temperature $90^{\circ} \mathrm{C}$ ), $\mathrm{B}_{1}$ (reagent ratio of epoxy chloropropane $10 \mathrm{~mL}$ : triethylenetetramine $5 \mathrm{~mL}$ ), $\mathrm{C}_{2}$ (etherification time $1 \mathrm{~h}$ ), $\mathrm{D}_{3}$ (amination time $3 \mathrm{~h}$ ).

\section{Structural and morphological analysis before and after modification of jute \\ 1) Infrared Characterization of jute before and after modification}

The surface modification of the jute fiber before and after modification was confirmed by FTIR. As shown in Fig.1, peaks of $3200-3700 \mathrm{~cm}-1$ were ascribed to the N-H stretching vibration significantly, near the peak of $1600 \mathrm{~cm}-1$ was the $-\mathrm{NH} 2$ bending vibration, $1568 \mathrm{~cm}-1$ department to -NH bending vibration absorption peak, $1260 \mathrm{~cm}-1$ was - CN stretching vibration. Infrared spectrum analysis showed that after reaction amino groups were grafted successfully on the surface of jute ${ }^{[10]}$

\section{2) SEM analysis}

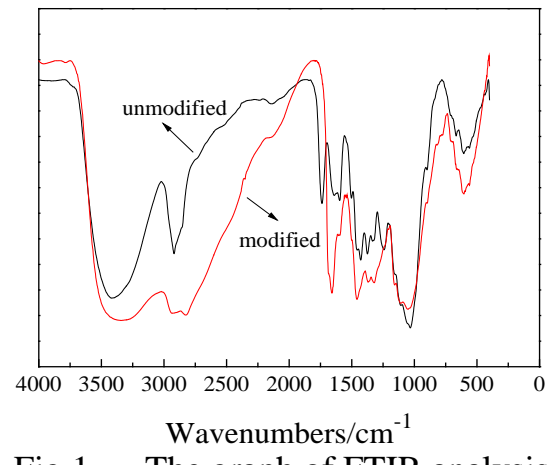

We used the optimal reaction conditions to prepare jute modified materials, and the adsorption capacity was measured obtaining at $120.048 \mathrm{mg} \mathrm{g}^{-1}$, at the same time, the saturated adsorption of the unmodified jute was only $7.694 \mathrm{mg}^{-1} \mathrm{~g}^{-1}$, after the mass fraction of $15 \% \mathrm{NaOH}$ treatment, jute adsorption capacity was $10.076 \mathrm{mg} \cdot \mathrm{g}^{-1}$.

Through the SEM test on unmodified, alkali treatment and modified jute magnified 5000 times, we could directly observe the surface change of different treatment on jute. As can be seen from Figure 2, before modification, the surface of jute (a) was covering a lot of gum; jute after alkali treatment (b) was bundle, the possible reason was because of pretreated with alkaline $\mathrm{NaOH}$ solution, the glial layer was damaged, and colloidal low molecular weight materials of jute surface such as pectin, lignin was dissolved, making the inside of the cellulose exposed ${ }^{[5]}$. That is conducive to the grafting reaction between cellulose and modified material. The surface groove 
of modified jute (c) was conducive to the adsorption reaction. This is consist with the abovedescribed adsorption capacity before and after the modification. The results showed that in pretreatment and grafting reaction, the surface structure of jute was obviously changed, and the adsorption quantity improved greatly. To determine the impact of the grafting reaction, the mechanical strength was measured before and after modification jute.

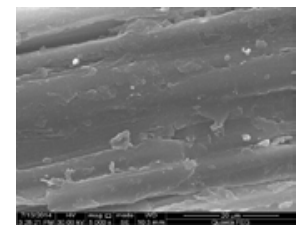

(a)

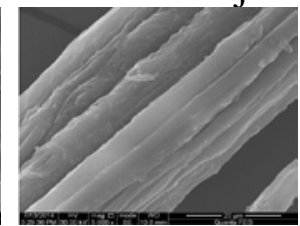

(b)

\section{3) mechanical strength analysis}

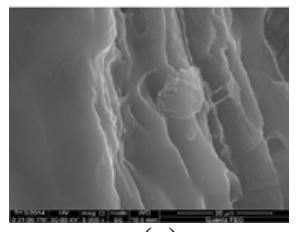

(c)

(a) unmodified (b) alkali treatment; (c) modified;

Figure 2 SEM analysis

Choosing the thickness was relatively uniform and the diameter was around $1 \mathrm{~mm}$ before and after modification, in the same operating conditions the mechanical properties of jute was test, and each group experiment was repeated 5 times. As apparent from Table 4, after alkali treatment the breaking force of jute changed significantly, the jute strength decreased much less after grafting reaction, which was consistent with the results of SEM image, namely because of pretreatment, the surface structure of jute was damaged, thus reduced its mechanical strength. The maximum load of modified jute was decreased significantly, but still could meet the needs of the hydraulic shear resistance, did not affect the use of the emergency in water treatment. After alkali treatment, the extension performance has a certain increase, probably because colloidal substances on the surface of the jute were destroyed to expose the internal base of cellulose, lignin, etc, making its extension performance improved. Probably because of the chemical reaction that it extends the performance of the modified somewhat lower, but still higher than the pre-modified jute.

Table 4 Jute mechanics index

\begin{tabular}{ccc}
\hline Jute & Breaking force/N & Breaking elongation /\% \\
\hline unmodified & $50.489 \pm 7.488$ & $1.779 \pm 0.413$ \\
alkali treatment & $15.105 \pm 0.718$ & $3.839 \pm 0.894$ \\
modified & $13.817 \pm 4.341$ & $2.161 \pm 0.236$ \\
\hline
\end{tabular}

\section{Experiment Experiments}

1) Effect of Temperature

As shown in Fig.3, the higher adsorption capacity obtained at a relatively higher temperature. Obviously, the temperature rise from $10^{\circ} \mathrm{C}$ to $30^{\circ} \mathrm{C}$, the maximum adsorption capacity of the modified jute increased from $67.984 \mathrm{mg} \mathrm{g}^{-1}$ to $121.045 \mathrm{mg} \cdot \mathrm{g}^{-1}$. Adsorption capacity of unmodified jute varies small with temperature, and the adsorption volume in $7 \mathrm{mg} \cdot \mathrm{g}^{-1}$, far less than the modified jute. This is consistent with the SEM diagram, namely after the grafting reaction of jute, changes in surface morphology is conducive to adsorption reaction. 


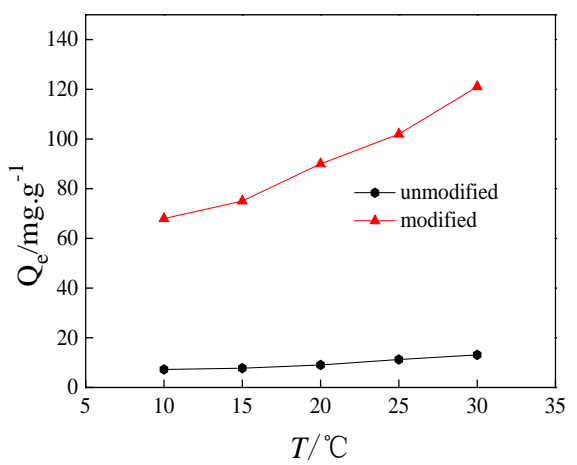

\section{2) Effect of pH}

Fig.3 Effect of temperatures T on removal of $\mathrm{Cu}(\mathrm{II})$

Modified jute for $\mathrm{Cu}$ (II) adsorption effect along with the change of solution $\mathrm{pH}$ is shown in figure 4. As can be seen from Figure 4, when $\mathrm{pH}$ ranged from 4 to 6, the adsorption capacity of modified jute for $\mathrm{Cu}$ (II) was higher. May be due to lower $\mathrm{pH}$, there was a large number of protons in the solution, part of the amino modified jute could proton reaction with water and hydrogen ions, then produced - $\mathrm{NH}^{3+}$ with a positive charge, and produced an electrostatic repulsion with $\mathrm{Cu}$ (II) ${ }^{[3 / 9]}$, resulting in low adsorption on $\mathrm{Cu}$ (II); when $\mathrm{pH}$ was about 5 , the free $\mathrm{Cu}$ (II) ion was abundance in solution, that was conducive to modified jute adsorption $\mathrm{Cu}$ (II). When the $\mathrm{pH}$ was too high, $\mathrm{Cu}$ (II) was adsorbed by water and formed $\mathrm{Cu}(\mathrm{OH})_{2}$, that was not conducive to $\mathrm{Cu}$ (II) complex with amino. The $\mathrm{pH}$ about $\mathrm{Cu}$ (II) solution is generally between 4 and 6, so in experimental operation, we can not adjust the $\mathrm{pH}$ of solution.

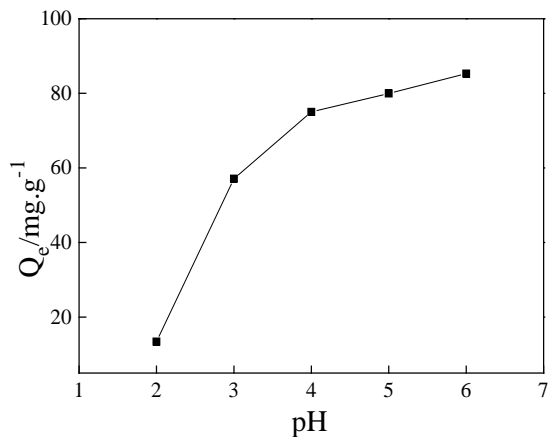

\section{3) Effect of coexisting ions}

Fig.4 Effect of $\mathrm{pH}$ on removal of $\mathrm{Cu}(\mathrm{II})$

In order to determine the influence of coexisting ions on the adsorption of modified jute, we choose $\mathrm{K}^{+}, \mathrm{Na}^{+}, \mathrm{Ca}^{2+}$ and $\mathrm{Mg}^{2+}$ four kinds of common interfering ions in natural water as the experiment. These coexisting ions on $\mathrm{Cu}$ (II) removal efficiency is shown in figure 5 . The figure 5 shown that when there were no interference ions, the saturated adsorption capacity of modified jute for $\mathrm{Cu}$ (II) was $81.717 \mathrm{mg} . \mathrm{g}^{-1}$; and there were interfering ions coexisting, modified jute for $\mathrm{Cu}$ (II) adsorption capacity remained at higher levels. Possibly because these ions were no empty tracks available to complex ions.

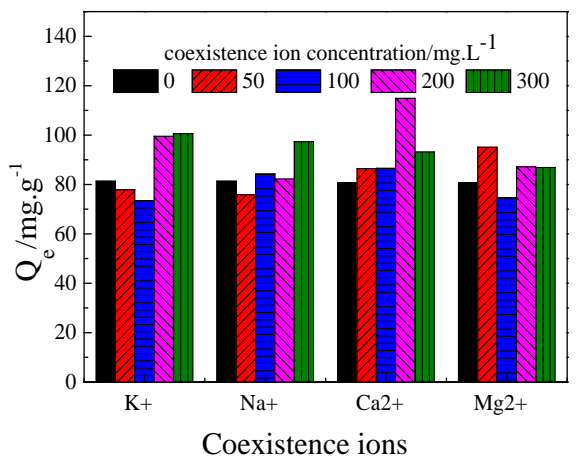

Fig.5 Effect of coexistence ion on removal of $\mathrm{Cu}$ (II)

\section{The adsorption kinetics study}

Jute before and after modification on $\mathrm{Cu}$ (II) adsorption kinetic curve are shown in figure 6 . The 
figure 6 shown that adsorption quantity on modified jute increased sharply in 20min, after 20 min became slowly, until stable, that is modified jute adsorbed $\mathrm{Cu}$ (II) in about 20min to reach equilibrium. The modified jute on $\mathrm{Cu}$ (II) adsorption equilibrium quantity is $97.512 \mathrm{mg} . \mathrm{g}-1$, much higher than the unmodified jute equilibrium adsorption capacity of 7.694mg.g-1.

Kinetics of adsorption process is mainly used to describe the adsorption of solute rate, the data can be fitted by a kinetic model to infer its adsorption mechanism. Both of the unmodified and modified jute were analyzed by pseudo-first-order, pseudo-second order ${ }^{[8]}$, and the results are shown in table 5. Quasi secondary dynamics equation has the significance level to describe the adsorption kinetics, and can well describe the adsorption process; theoretical equilibrium adsorption capacity before and after modification of jute were 7.959 mg.g-1 and $100.705 \mathrm{mg} . g-1$, in accordance with the experimental data.

\section{Adsorption isotherms study}

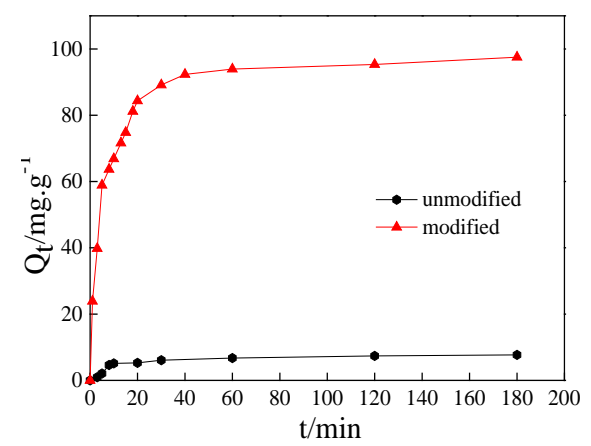

Fig.6 Cu (II) adsorption kinetics of jute

At $25^{\circ} \mathrm{C}$, we configured a series of different concentrations of $\mathrm{Cu}$ (II) solution, adding suitable amount of modified jute to $100 \mathrm{ml} \mathrm{Cu}$ (II) solution, and the adsorption process designed for $12 \mathrm{~h}$ at constant temperature water. After adsorption we determined the concentration of $\mathrm{Cu}$ (II) solution, and obtained the adsorption isotherm of modified jute, and its Langmuir isotherm and Frundlich fitting results shown in Figure 7 and Table 6. The figure 7 shown that modified jute for $\mathrm{Cu}$ (II) adsorption quantity increased with the initial concentration, and the maximum adsorption capacity can reach 112.981mg.g-1, The table 6 shows that the adsorption process conforms to the Langmuir theory ${ }^{[2]}$, which is more homogeneous modification of the surface properties of materials; the adsorption process is single dynamic adsorption.

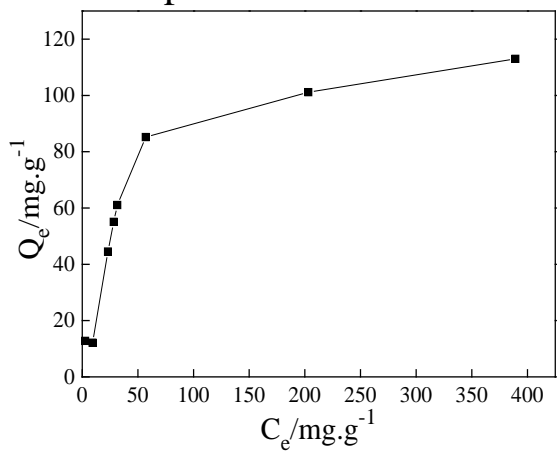

Fig.7 The isothermal line of adsorption of modified jute against $\mathrm{Cu}$ (II)

Table 5 Regression coefficient of $\mathrm{Cu}^{2}$ adsorption kinetics

\begin{tabular}{|c|c|c|c|c|c|c|}
\hline \multirow{2}{*}{ Jute fiber } & \multicolumn{3}{|c|}{ First order kinetic model } & \multicolumn{3}{|c|}{ Second order kinetic model } \\
\hline & $\mathrm{qe}_{1} / \mathrm{mg}^{-\mathrm{g}^{-}}$ & $\mathrm{k}_{1} / \mathrm{min}^{-1}$ & $\mathrm{R}^{2}$ & $\mathrm{q}_{\mathrm{e}} / \mathrm{mg}_{\mathrm{g}} \mathrm{g}^{-1}$ & $\mathrm{k}_{2} / \mathrm{g} \cdot(\mathrm{mg} \cdot \mathrm{min})^{-1}$ & $\mathrm{R}^{2}$ \\
\hline $\begin{array}{l}\text { unmodified } \\
\text { modification }\end{array}$ & $\begin{array}{r}4.828 \\
47.785 \\
\end{array}$ & $\begin{array}{l}0.0274 \\
0.0416 \\
\end{array}$ & $\begin{array}{l}0.871 \\
0.872 \\
\end{array}$ & $\begin{array}{c}7.959 \\
100.705 \\
\end{array}$ & $\begin{array}{c}0.0154 \\
0.00431 \\
\end{array}$ & $\begin{array}{l}0.998 \\
0.997 \\
\end{array}$ \\
\hline \multicolumn{7}{|c|}{ Table 6 Regression coefficient of $\mathrm{Cu}^{2+}$ adsorption isotherm } \\
\hline \multicolumn{4}{|c|}{ Langmuir } & \multicolumn{3}{|c|}{ Freundlich } \\
\hline $\mathrm{Q}_{\mathrm{m}} / \mathrm{mg} \cdot \mathrm{g}^{-1}$ & & $\mathrm{ng}^{-1}$ & $\mathrm{R}^{2}$ & $\mathrm{~K}_{\mathrm{F}}$ & $\mathrm{n}$ & $\mathrm{R}^{2}$ \\
\hline
\end{tabular}




\section{Conclusions}

The grafting reaction temperature on jute fiber modification effect bigger, and under the condition of optimum modification, modified jute for $\mathrm{Cu}$ (II) adsorption capacity can reach $120 \mathrm{mg}$. $\mathrm{g}^{-1}$, far higher than the $7 \mathrm{mg}$. g-1 before modification. The mechanical strength of modified jute has decreased, but still meets the actual needs. Heating is conducive to the adsorption reaction; neutral acidic environment on modified jute removing $\mathrm{Cu}$ (II) advantageously; water common coexist ions such as $\mathrm{K}^{+}, \mathrm{Na}^{+}, \mathrm{Ca}^{2+}, \mathrm{Mg}^{2+}$, modified jute for $\mathrm{Cu}$ (II) adsorption has certain promoting effect.

\section{Acknowledgements}

This work was funded by National water pollution control and management technology major projects (2012ZX07205-005). ${ }^{*}$ Corresponding authors is T. ZHENG, associate Professor. Email address: zhengtong@hit.edu.cn.

\section{Reference}

[1] DONG Xiao-yan, SHI Li-wei. 2011. Spectrophotometric determination of trace copper in drinking water with biscyclohexanone oxaldihydrazone[J]. Chinese Journal of Health Laboratory Technology, 4(21):814-816.

[2] DU Zhao-lin. 2012, Study on Emergency Disposal Materials and Equipment of Copper Pollution in Water [M]. Hei Longjiang: Harbin Institute of Technology.

[3] Hena S. 2010. Removal of chromium hexavalent ion from aqueous solutions using biopolymer chitosan coated with poly 3-methyl thiophene polymer [J]. Journal of Hazardous Materials, 181(1):474-479.

[4] HUANG Jun, ZHAI Hua-min, WANG Xiao-jun. 2010. Synthesis and Spectroscopic Study of Polyamine-Type Cellulose-Based Chelating Fiber [J].Spectroscopy and Spectral Analysis, 6(30):1606-1609.

[5] Larous A S, Meniai H. 2005. Experimental study of the removal of copper from aqueous solutions by adsorption using sawdust [J] European Desalination Society, 185:483-490.

[6] Liu Qingsong, Zheng Tong, Wang Peng, et al. 2010. Adsorption isotherm, kinetic and mechanism studies of some substituted phenols on activated carbon fibers [J]. Chemical Engineering Journal, 157:348-356.

[7] Liu Changkun, Bai Renbi, Liang Hong. 2006. Diethylenetriamine-grafted poly(glycidyl methacrylate) adsorbent for effective copper ion adsorption[J]. Journal of Colloid and Interface Science, 303(1): 99-108.

[8] Shukla S R. 2005. Adsorption of $\mathrm{Cu}$ (II), Ni (II) and Zn (II) on modified jute fibers[J]. Bioresource Technology, 96: 1430-1438.

[9] Wan Ngha W S. Hanafiah M A K M. 2008. Removal of heavy metal ions from wastewater by chemically modified plant wwastes as adsorbents: A review [J] Bioresource Technology, 99: 3935-3948.

[10] XU Chao, LIU Fu-qiang, LING-Chen, et al.2014. Research Progress in Adsorption Performance of Heavy Metal Ions with Polyamine Chelating Adsorbents: A Review[J].Ion Exchange and Adsorption, ,30(1): 87-96.

[11] ZHAO Lei. 2010. Effect of Surface Modification on the Jute Fiber Properties, Shanghai Wool \& Jute Journal, (2):2-5.

[12] ZHENG Tong, DU Zhao-lin, HE Yu-qiang, et al., 2013. Analysis on Current Treatment 
Method of Heavy Metal Pollution in Water Bodies and Emergency Disposal Strategy, China Water \& Wastewater, 9(6): 18-21. 